\title{
Implementasi Kesiapan UKM di Kota Malang di Era Revolusi Industri 4.0
}

\author{
Priska Wulan Ndari ${ }^{1, *}$, Fuad Achmadi ${ }^{2}$, Prima Vitasari ${ }^{3}$ \\ 1,2,3 Program Studi Teknik Industri, Program Pascasarjana, Institut Teknologi Nasional Malang \\ ${ }^{*}$ E-mail : priskawulandari21@gmail.com
}

\begin{abstract}
Abstrak
Dinas Koperasi dan UKM Kota Malang mencatat bahwa sampai dengan Maret tahun 2020 terdapat sekitar 118.000 UKM dengan berbagai level. Di sisi lain, berdasarkan data pelatihan start up digital. Digital Lounge Telkom Malang yaitu 92 UKM di Kota Malang terdapat kendala dalam kesiapan industri 4.0. Tujuan penelitian ini adalah mendeskripsikan implementasi kesiapan UKM di Kota Malang di Era Revolusi Industri 4.0. Teknik pengambilan sampel dilakukan dengan purposive sampling yaitu dipilih UKM klaster menengah berteknologi digital 4.0. Jumlah sample yang diambil sebanyak 50 UKM. Metode yang digunakan dalam penelitian adalah pengukuran indeks kesiapan industri 4.0. Berdasarkan hasil kuesioner disimpulkan bahwa dari 50 responden, hanya sebagian kecil responden yang siap menghadapi Revolusi Industri 4.0 sisanya tidak siap, siap bersyarat dan kesiapan dasar. Kesiapan UKM di Kota Malang di era 4.0 sangat didominasi oleh usia muda yang tanggap terhadap teknologi internet of thing, jenis kelamin laki-laki serta pemilik UKM belum pernah mengikuti pelatihan.
\end{abstract}

Kata Kunci : UKM, Revolusi Industri 4.0, Teknologi Digital

\section{Pendahuluan}

Industri 4.0 sebagai integrasi teknis CPS ke dalam manufaktur dan logistik dan penggunaan IoT dalam Revolusi Industri 4.0 diperkenalkan oleh Profesor Klaus Schwab, ditandai dengan cyber-physical yang digunakan oleh industri, konektivitas secara virtual dari semua lini antara manusia, mesin dan data. Industri 4.0 masih visioner namun suatu konsep yang realistis, termasuk Internet of Things, smart manufacturing, dan cloud based manufacturing $[1 ; 2 ; 3 ; 5 ; 6 ; 7 ; 8]$. Revolusi industri 4.0 dikenal dengan revolusi digital karena terjadi proliferasi komputer dan otomatisasi pencatatan disemua bidang, karena otomatisasi dan konektivitas disebuah bidang akan membuat perubahan secara signifikan di dunia industri dan persaingan kerja menjadi tidak linier. Salah satu karakteristik dari revolusi industri 4.0 menerapkan pengaplikasikan kecerdasan buatan atau artificiall intellegent [9;10]. Ada 5 dimensi perusahaan terkait kesiapan Industri 4.0. Konsep Industri 4.0 dan model pengukuran dari IMPULS Indutrie 4.0 readiness dijadikan sebagai acuan dalam penelitian ini karena model pengukuran tersebut memberikan penjelasan yang lengkap dan detail mengenai dimensi, variabel dan pendekatan yang digunakan dalam pengukuran. 5 dimensi perusahaan terkait kesiapan Industri 4.0

UKM merupakan salah satu tulang punggung perekonomian Indonesia. UKM menyumbang 99\% dari seluruh bisnis yang ada, memperkerjakan $89 \%$ angkatan kerja sektor swasta dan berkontribusi 57\% pada produk domestik bruto (PDB). Kondisi ini menuntut UKM harus mampu menghadapi tantangan Revolusi Industri 4.0 tetapi sebagian kecil UKM yang mampu menghadapi tantangan Revolusi Industri 4.0. Ketidaksiapan berupa adopsi teknologi informasi dikarenakan biaya tinggi yang harus dikeluarkan sedangkan pendapatan yang diterima jauh lebih rendah.Penerimaan Pendapatan Kota Malang salah satunya bersumber dari sentra UKM[7]. UKM tersebar pada 5 kecamatan di Kota Malang dengan berbagai jenis skala usaha. Dalam making Malang 4.0 kesiapan UKM dalam Revolusi Industri 4.0,Pemerintah Kota Malang melalui Bagian Pengembangan Perekonomian Setda Kota Malang yang bekerjasama dengan Telkom Malang serta Jagoan Hosting, mengadakan pelatihan start up digital dengan berbagai komuitas dan Kamar Dagang Industri Kota Malang.Hasil UKM mengalami kendala antara lain kurang optimis terhadap teknologi, kurangnya permodalan, keterampilan manajerial dan 
beroperasi, kurangnya pelatihan tentang optimalisasi produksi, kurang inovasi terhadap teknologi dan lemahnya kualitas produk dan pemasaran[7].

\section{Metode Penelitian}

Penelitian ini menggunakan instrumen yang terdiri dari instrumen wawancara berupa handphone untuk berkomunikasi dengan responden pemilik UKM. Alat tulis untuk mencatat informasi narasumber dan daftar pertanyaan dilakukan melalui google form serta kuesioner menggunakan metode tertutup, dimana kemungkinan pilihan jawaban sudah ditentukan terlebih dahulu dan responden tidak diberikan alternatif jawaban. Pengujian Instrumen kuesioner dilakukan dengan model pengukuran teknologi readines index industri 4.0 [7;9].Data sekunder pada penelitian ini adalah study pustaka[7;9]. Data primer pada penelitian ini adalah dari hasil wawancara dan kuesioner [7]

\section{Hasil dan Pembahasan}

Deskripsi responden sebanyak 50 orang pemilik UKM di Kota Malang yang sudah berteknologi 4.0 dapat digambarkan dalam tabel berikut:

Tabel 1. Deskripsi Responden

\begin{tabular}{|c|c|c|}
\hline \multicolumn{2}{|c|}{ Karakteristik Responden } & Presentase $(\%)$ \\
\hline \multirow[t]{2}{*}{ Jenis Kelamin } & Laki-laki & $77,78 \%$ \\
\hline & Perempuan & $22,22 \%$ \\
\hline \multirow[t]{4}{*}{ Usia } & 25-30 tahun & $47,22 \%$ \\
\hline & 31-40 tahun & $31,94 \%$ \\
\hline & 41-50 tahun & $18,06 \%$ \\
\hline & $>55$ tahun & - \\
\hline \multirow[t]{2}{*}{ Lama Usaha } & $<5$ tahun & $69,84 \%$ \\
\hline & $>5$ tahun & $30,16 \%$ \\
\hline \multirow{3}{*}{$\begin{array}{l}\text { Teknologi yang } \\
\text { digunakan }\end{array}$} & Cloud Computing & $26,98 \%$ \\
\hline & Smart manufacturing & $3,17 \%$ \\
\hline & Internet of thing & $69,84 \%$ \\
\hline \multirow{3}{*}{$\begin{array}{l}\text { Pendidikan } \\
\text { terakhir }\end{array}$} & SMA Sederajat & $6,35 \%$ \\
\hline & $\mathrm{S} 1$ & $90,48 \%$ \\
\hline & $\mathrm{S} 2$ & $3,17 \%$ \\
\hline \multirow[t]{2}{*}{ Pelatihan } & Pernah mengikuti & $15,87 \%$ \\
\hline & Tidak pernah mengikuti & $84,13 \%$ \\
\hline
\end{tabular}

Uji instrumen juga dilakukan dengan uji validitas dan reliabilitas dengan hasil sebagai berikut:

Tabel 2. Uji Validitas Instrumen Penelitian

\begin{tabular}{|c|c|c|c|c|}
\hline \multirow{2}{*}{ Variabel } & \multirow{2}{*}{ Item } & \multicolumn{2}{|c|}{ Uji Validitas } & \multirow{2}{*}{ Keputusan } \\
\hline & & Korelasi (r) & Sign.(p) & \\
\hline \multirow[t]{4}{*}{$\mathrm{X} 1$} & $\mathrm{X} 1.1$ & 0.930 & 0.000 & Valid karena Sign. $(\mathrm{p})<$ Korelasi $(\mathrm{r})$ \\
\hline & $\mathrm{X} 1.2$ & 0.927 & 0.000 & Valid karena Sign. $(\mathrm{p})<$ Korelasi $(\mathrm{r})$ \\
\hline & $\mathrm{X} 1.3$ & 0.870 & 0.000 & Valid karena Sign. $(\mathrm{p})<$ Korelasi $(\mathrm{r})$ \\
\hline & $\mathrm{X} 1.4$ & 0.877 & 0.000 & Valid karena Sign. $(\mathrm{p})<$ Korelasi $(\mathrm{r})$ \\
\hline \multirow[t]{2}{*}{$\mathrm{X} 2$} & $\mathrm{X} 2.1$ & 0.968 & 0.000 & Valid karena Sign. $(\mathrm{p})<$ Korelasi $(\mathrm{r})$ \\
\hline & $\mathrm{X} 2.2$ & 0.953 & 0.000 & Valid karena Sign. $(\mathrm{p})<$ Korelasi $(\mathrm{r})$ \\
\hline
\end{tabular}




\begin{tabular}{|c|c|c|c|c|}
\hline & $\mathrm{X} 2.3$ & 0.968 & 0.000 & Valid karena Sign. $(\mathrm{p})<$ Korelasi $(\mathrm{r})$ \\
\hline & $\mathrm{X} 2.4$ & 0.949 & 0.000 & Valid karena Sign. $(\mathrm{p})<$ Korelasi $(\mathrm{r})$ \\
\hline \multirow[t]{4}{*}{$\mathrm{X} 3$} & $\mathrm{X} 3.1$ & 0.942 & 0.000 & Valid karena Sign. $(\mathrm{p})<$ Korelasi $(\mathrm{r})$ \\
\hline & $\mathrm{X} 3.2$ & 0.915 & 0.000 & Valid karena Sign. $(\mathrm{p})<$ Korelasi $(\mathrm{r})$ \\
\hline & $\mathrm{X} 3.3$ & 0.957 & 0.000 & Valid karena Sign. $(\mathrm{p})<$ Korelasi $(\mathrm{r})$ \\
\hline & $\mathrm{X} 3.4$ & 0.936 & 0.000 & Valid karena Sign. $(\mathrm{p})<$ Korelasi $(\mathrm{r})$ \\
\hline \multirow[t]{4}{*}{ Y1 } & Y1.1 & 0.938 & 0.000 & Valid karena Sign. $(\mathrm{p})<$ Korelasi $(\mathrm{r})$ \\
\hline & Y1.2 & 0.943 & 0.000 & Valid karena Sign. $(\mathrm{p})<$ Korelasi $(\mathrm{r})$ \\
\hline & Y1.3 & 0.904 & 0.000 & Valid karena Sign. $(\mathrm{p})<$ Korelasi $(\mathrm{r})$ \\
\hline & Y1.4 & 0.936 & 0.000 & Valid karena Sign. $(\mathrm{p})<$ Korelasi $(\mathrm{r})$ \\
\hline \multirow[t]{6}{*}{$\mathrm{Y} 2$} & Y2.1 & 0.913 & 0.000 & Valid karena Sign. $(\mathrm{p})<$ Korelasi $(\mathrm{r})$ \\
\hline & Y2.2 & 0.905 & 0.000 & Valid karena Sign. $(\mathrm{p})<$ Korelasi $(\mathrm{r})$ \\
\hline & Y2.3 & 0.894 & 0.000 & Valid karena Sign. $(\mathrm{p})<$ Korelasi $(\mathrm{r})$ \\
\hline & Y2.4 & 0.911 & 0.000 & Valid karena Sign. $(\mathrm{p})<$ Korelasi $(\mathrm{r})$ \\
\hline & Y2.5 & 0.892 & 0.000 & Valid karena Sign. $(\mathrm{p})<$ Korelasi $(\mathrm{r})$ \\
\hline & Y2.6 & 0.839 & 0.000 & Valid karena Sign. $(\mathrm{p})<$ Korelasi $(\mathrm{r})$ \\
\hline
\end{tabular}

Berdasarkan tabel tersebut di atas dapat dijelaskan bahwa semua variabel mempunyai jumlah item instrumen yang berbeda yang dikembangkan oleh peneliti dan memenuhi persyaratan uji validitas karena masing-masingnya memiliki nilai signifikansi (p) lebih kecil dari alpha 0,05.

Tabel 3. Hasil Uji Reliabilitas Instrumen

\begin{tabular}{|c|c|c|}
\hline Variabel & $\begin{array}{c}\text { Alpha Cronbach } \text { (based on } \\
\text { standardized items) }\end{array}$ & Keterangan \\
\hline $\mathrm{X} 1$ & 0.923 & Sangat tinggi/reliabel \\
\hline $\mathrm{X} 2$ & 0.971 & Sangat tinggi/reliabel \\
\hline $\mathrm{X} 3$ & 0.954 & Sangat tinggi/reliabel \\
\hline $\mathrm{Y} 1$ & 0.948 & Sangat tinggi/reliabel \\
\hline $\mathrm{Y} 2$ & 0.949 & Sangat tinggi/reliabel \\
\hline
\end{tabular}

Berdasarkan tabel tersebut bahwa semua butir-butir item sebagai pengukur dari variabelvariabel yang diamati adalah reliabel, karena nilai alpha cronbach dari variabel-variabel yang diuji memiliki SIA (Standardized Item Alpha) lebih besar dari nilai reliabilitas yang diperbolehkan, yaitu 0,6.

Variabel organisasi merupakan dimensi teknologi, operasional serta pekerja dan budaya. Variabel inovativeness merupakan dimensi kepemimpinan dan strategi serta variabel optimism merupakan dimensi pemahaman industri 4.0 Langkah selanjutnya adalah menghitung indeks kesiapan (ID) untuk masing-masing dimensi UKM. Indeks kesiapan dimensi adalah nilai rata-rata dari indeks kesiapan variabel (VDi) dalam dimensi tersebut atau dapat dituliskan dalam rumus[9]

$$
I D \frac{=\sum_{I=1}^{n} \quad V D i}{n}
$$

Dimana:

ID : Indeks kesiapan dimensi

$V D i$ : Nilai variabel ke-i dalam dimensi

$n$ : Jumlah variabel dalam dimensi

Diagram radar digunakan untuk menggambarkan indeks kesiapan Industri 4.0 secara keseluruhan sehingga UKM dapat menilai pada dimensi mana telah memiliki tingkat kesiapan yang tinggi atau rendah terkait Industri 4.0. [9]. Berikut hasil diagram radar untuk responden 1. 


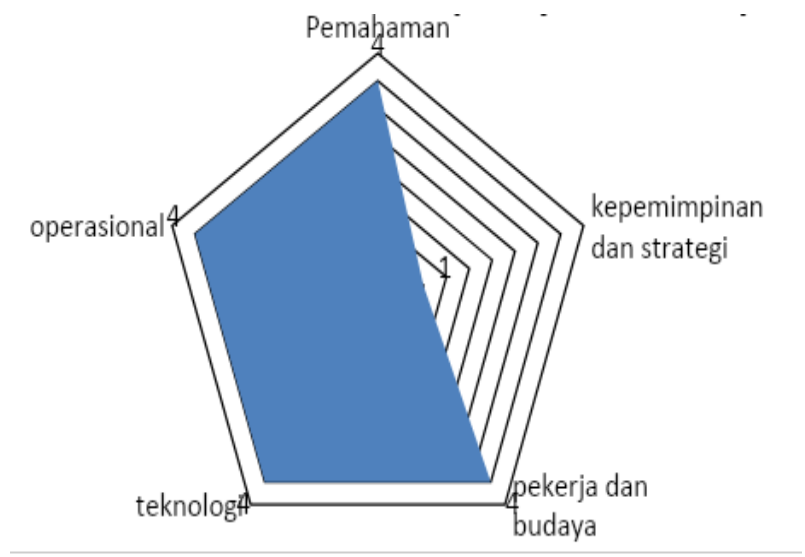

Gambar 1. Diagram Radar Kesiapan UKM di Kota Malang di Era Revolusi Industri 4.0 (Responden 1)

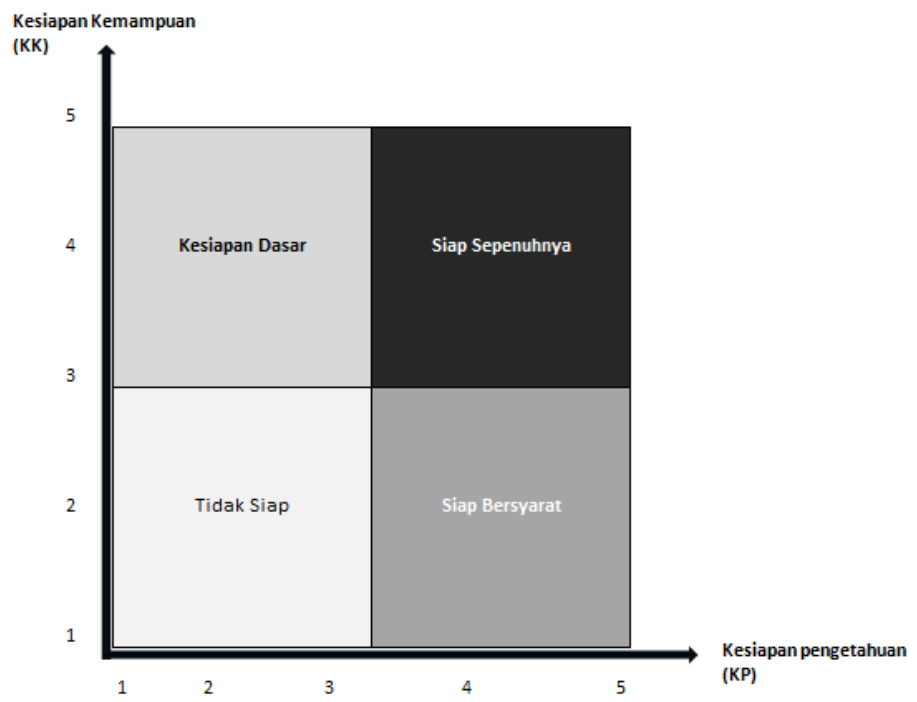

Gambar 2. Matriks Kuadran Kesiapan UKM dalam menghadapi Revolusi Industri 4.0

1. UKM dalam menyusun strategi dan rencana kerja Industri 4.0 bisa melihat hasil pengukuran aspek kesiapan Industri, yaitu aspek "Pengetahuan" $(K P)$ dan aspek "Kemampuan Sumber Daya" $(K K)$ digambarkan dalam bentuk matriks kuadran. UKM yang memiliki nilai $K P$ rendah dan nilai $K K$ rendah berada dalam kuadran 1, level "Tidak Siap" dalam arti UKM tidak memiliki pengetahuan yang cukup dan tidak memiliki kemampuan sumber daya yang diperlukan untuk memulai proses transformasi Industri 4.0. UKM yang berada di kuadran 1 memerlukan arahan yang tinggi dalam pemahaman serta kepemimpinan dan strategi terkait Industri 4.0 serta dukungan yang tinggi untuk meningkatkan kemampuan sumber daya pekerja, teknologi dan operasional.

2. UKM yang memiliki nilai $K P$ tinggi dan nilai $K K$ rendah berada dalam kuadran 2, level "Siap Bersyarat" dalam arti UKM sudah memiliki pengetahuan yang cukup terkait Industri 4.0, tetapi tidak memiliki kemampuan sumber daya yang diperlukan untuk memulai proses transformasi Industri 4.0. UKM yang berada di kuadran 2 memerlukan arahan yang rendah tetapi memerlukan dukungan yang tinggi untuk meningkatkan kemampuan sumber dayanya agar segera dapat memulai proses transformasi Industri 4.0.

3. UKM yang berada di kuadran 3, level "Kesiapan Dasar" adalah UKM yang memiliki $K P$ rendah dan nilai $K K$ tinggi. UKM ini sudah memiliki kemampuan sumber daya untuk memulai proses transformasi Industri 4.0, akan tetapi belum memiliki pengetahuan yang memadai. UKM yang berada di kuadran ini perlu mendapatkan arahan yang tinggi agar memiliki pengetahuan terkait Industri 4.0 namun memerlukan dukungan yang rendah. Apabila UKM ini telah memiliki 
pengetahuan yang cukup, UKM ini dapat dengan segera memulai proses transformasi Industri 4.0 karena pada dasarnya sudah memiliki kemampuan

4. UKM yang berada di kuadran 4, level "Siap Sepenuhnya" adalah UKM yang memiliki baik nilai $K P$ maupun nilai $K K$ tinggi. UKM yang berada di kuadran ini sudah siap sepenuhnya untuk memulai proses transformasi Industri 4.0. UKM yang berada di kuadran 4 ini sudah memiliki pengetahuan yang cukup terkait Industri 4.0 dan memiliki kemampuan sumber daya yang diperlukan, memerlukan arahan dan dukungan yang rendah.

\section{Kesimpulan}

Berdasarkan hasil kuesioner dari 50 responden, terdapat 19 responden yang siap menghadapi Revolusi Industri sisanya tidak siap, siap bersyarat dan kesiapan dasar. Kesiapan UKM di Kota Malang di Era Revolusi Industri 4.0 sangat didominasi oleh usia muda yang tanggap terhadap teknologi dengan jenis kelamin laki-laki dan teknologi yang digunakan UKM terdiri atas cloud computing sebesar 26,98\%, smart manufacturing 3,17\% dan internet of thing sebesar 69,84\% dengan distribusi lama usaha $<5$ tahun sebesar $69,84 \%$ dan lama usaha $>5$ tahun sebesar 30,16\%. Pemilik UKM yang tidak pernah mengikuti pelatihan sebesar $84,13 \%$ dan pernah mengikuti pelatihan UKM sebesar 15,87\%

\section{Daftar Pustaka}

[1] Schumacher, A., Erol, S., \& Sihn, W. 2016. Maturity model for assessing Industry 4.0 readiness and maturity of manufacturing enterprises, Procedia CIRP, 52, 161-166.

[2] C. Faller and D. Feldmüller. 2015. Industry 4.0 Learning Factory for regional SMEs, Procedia CIRP, 32, 88-91.

[3] Gokalp, E., Şener, U., and Eren, P., E. 2017. Development of an assessment model for Industry 4.0: Industry 4.0-MM. International Conference on Software Process Improvement and Capability Determination, Software Process Improvement and Capability Determination, 128-142.

[4] Kementrian Perindustrian Republik Indonesia. 2018. Kemenperin Luncurkan Roadmap Implementasi Industri 4.0, 1-8.

[5] Aboelmaged, M. G. 2014. Predicting e-readiness at Firm Level: An Analysis of Technological, Organizational, and Enviromental (TOE) Effects on e-maintenance Readiness in Manufacturing Firms. International Journal of Information Management, 34, 639-651.

[6] Harahap, N. J., \& Rafika, M. 2020. Industri 4.0: Industrial Revolution 4.0: And The Impact On Human Resources. Jurnal Ekonomi Bisnis dan Manajemen, 7 (1). 89-96.

[7] Puspasari, R., \& Santoso, D. T. 2019. Pengembangan Model Kesiapan UMKM di Era Revolusi Industri 4.0. Jurnal Media Teknik dan Sistem Industri, 3 (1), 37-42.

[8] Vaidya, S., Ambad, P., \& Bhosle, S. Industry 4.0 - A Glimpse. (2018). ProcediaManufacturing. 20, 233-238.

[9] Sen, T. H., Andhika, A., Ariyanti, F. D., \& Soebandrija, K. E. N. 2019. Pengembangan Model Pengukuran Kesiapan Industri 4.0 Untuk Perusahaan Manufaktur Di Indonesia. Jurnal Penelitian dan Aplikasi Sistem \& Teknik Industri (PASTI). 13(2), 106-120.

[10] Tjandrawina, R. R. 2016. Industri 4.0: Revolusi Industri Abad ini dan Pengaruhnya di Bidang kesehatan dan bioteknologi. Jurnal Medicinus, 29(1), 31-39. 